JOURNAL DE PHYSIQUE IV

Colloque C2, supplément au Journal de Physique III, Volume 5, février 1995

\title{
Martensitic and Related Transformations in Ni-Al Alloys
}

D. Schryvers

EMAT, RUCA, University of Antwerp, Groenenborgerlaan 171, B-2020 Antwerp, Belgium

\begin{abstract}
The present paper gives a review of results of recent studies investigating the fundamentals of the martensitic and related phase transformations in Ni-Al. For the former case, the emphasis will be on the microstructure of martensite plates. The latter include the metastable $\mathrm{Ni}_{2} \mathrm{Al}$ $\omega$-like and stable $\mathrm{Ni}_{5} \mathrm{Al}_{3}$ bainitic phases. These phases will be discussed in view of their atomic structure, nucleation, growth and effect on the martensitic transformation. A separate chapter will deal with precursor effects.
\end{abstract}

\section{INTRODUCTION}

The crystal structure of the stable equiatomic NiAl phase was first determined by Becker $\&$ Ebert to have a $\mathrm{CsCl}$ (B2) type structure [1], based on a bcc lattice; its unit cell is represented in fig. 1a. Gwyer showed that the composition range of this phase, then named $\beta$ phase and later to become the austenite parent phase, extends on the Ni-rich side of stoichiometric NiAl [2]. Later Bradley \& Taylor showed that this phase also exists on the Al-rich side of the equiatomic composition [3]. The first report of martensite structures in $\mathrm{Ni}-\mathrm{Al}$ was in 1951 by Guseva \& Makarov who showed the existence of a tetragonal phase in Ni-rich alloys [4]. Maxwell \& Grala for the first time used the term "martensite-like" in a technical report in 1954 [5]. In 1973 Enami, Nenno \& Shimizu corrected the first atomic model of the martensitic phase presented earlier by Rosen \& Goebel [6] and concluded on a simple $L 1_{0}$ unit cell based on an fct lattice, which perfectly corresponds with the pure displacive character of the transformation [7], as shown in fig. $1 b$.

At the $30^{\text {th }}$ annual EMSA meeting in 1972 Mohanty \& Rath presented the first transmission electron micrographs of the martensite phase in the Ni-Al system [8]. Their pictures clearly show heavy faulting inside the martensite plates and the authors indicate that in some cases these faults have been identified as $\{111\}_{\text {fct }}$ twins. Later several long period stackings of these twins were reported (for references see chapter 2). The first extensive report on the crystallography of the martensitic transformation was presented by Chakravorty \& Wayman [9]. The habit plane was experimentally determined to be close to the $\{21415\}$ family of the $\beta$ phase, confirming the theoretical predictions of the Bowles-Mackenzie theory $[10,11]$. In 
chapter 2 recent experimental results on the internal microstructure of the martensite plates will be reviewed and placed in perspective with new theoretical findings.

a

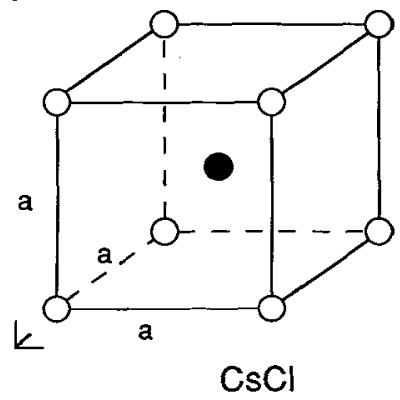

b

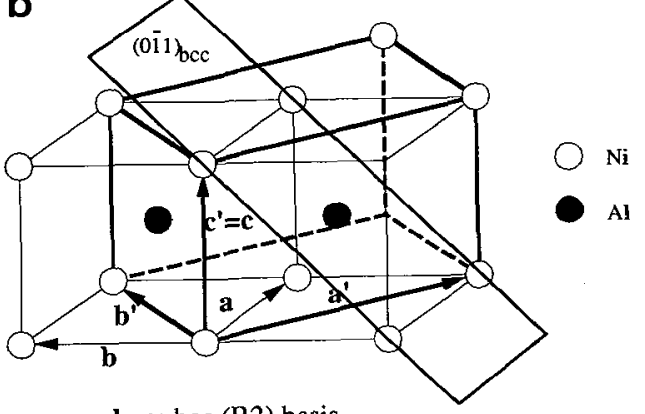

a, b, c: bcc (B2) basis

$\mathbf{a}^{\prime}, \mathbf{b}^{\prime}, \mathrm{c}^{\prime}$ : fct $(\mathrm{L} 10)$ basis

Figure 1. (a) Unit cell of the austenite B2 structure ( $\mathrm{CsCl}$ ordering) and (b) lattice correspondence between the austenite and martensite lattices.

The first report of shape memory behaviour in Ni-Al was presented by Enami \& Nenno in 1971 [12]. One year later the same issue was addressed by $\mathrm{Au} \&$ Wayman who investigated a number of Ni-Al alloys with different compositions and found the transformation to be thermoelastic with very small hysteresis $\left( \pm 10^{\circ}\right)$ and a very strong composition dependency of $\mathrm{M}_{\mathrm{S}}[13]$.

In the late sixties and early seventies experimental evidence of anomalies in the behaviour of physical parameters of the crystal lattices of $\beta$ phase alloys, including $\mathrm{Ni}-\mathrm{Al}$, and close to the martensitic transformation accumulated. The interpretation of the evolution of these anomalies in terms of premonitory behaviour for the ensuing transformation gained interest. The question to whether these effects are actually necessary for the transformation to occur is even today still open for discussion (see chapter 3). In fact, a large number of recent theoretical as well as experimental fundamental papers on this issue explicitly discuss or refer to the Ni-Al system, making this material a kind of model system for the study of precursor effects in displacive systems.

Recently more attention has been paid to the occurrence of secondary phases in the existency range of the martensite phase. Two of those, the metastable $\omega$-like $\mathrm{Ni}_{2} \mathrm{Al}$ and bainitic $\mathrm{Ni}_{5} \mathrm{Al}_{3}$ phase will be discussed further on (chapters 4 and 5). Also martensitic structures similar to those in binary $\mathrm{Ni}$-Al have been observed in ternary alloys based on this model system (see also chapter 2).

\section{FINE STRUCTURE OF Ni-AI MARTENSITE}

When describing the martensite lattice as a stacking of close packed planes the conventional Ramsdel notation for the fct lattice is $3 \mathrm{R}$, where the ordering is ignored. In a new scheme Otsuka, Ohba, Tokonami and Wayman apply the crystallographic relation between the austenite and martensite in a more systematic way and suggest a notation $2 \mathrm{M}$ (two atomic layers, monoclinic symmetry) [14]. Again the close packed planes of the product phase act as basal planes. The first periodic stacking sequence found in $\mathrm{Ni}-\mathrm{Al}$ 
martensite and based on a $\{111\}_{\mathrm{fel}}$ shear or twinning was reported in 1974 by Chandrasekaran \& Mukherjee in a 65 at\% $\mathrm{Ni}$ alloy in which the martensite lattice was shown to poses hexagonal symmetry [15]. In the new scheme its notation would be 20 . In 1982 Chandrasekaran \& Delaey showed evidence of a ten layer periodicity, which could be called 10M [16]. A few years earlier Reynaud had presented the first in-situ electron diffraction sequence of a cooled $\mathrm{Ni}$-Al sample going through the martensitic transformation temperature [17]. His set of five diffraction patterns now looks as an extremely important step towards the understanding of the martensitic transformation in $\mathrm{Ni}-\mathrm{Al}$. One of the patterns shows a row of 7 superreflections, indicating a stacking sequence of 7 close packed layers of the fct structure. Later Martynov, Enami, Khandros, Nenno \& Tkachenko used the notation $7 \mathrm{R}$ and showed that the observed $(5, \overline{2})$ stacking sequence of seven close packed planes is the same in thermal as in stress induced martensite [18,19]. In the scheme of Otsuka et al, this unit cell is now noted as $14 \mathrm{M}[14]$. The $(5, \overline{2})$ stacking was later confirmed by Schryvers \& Tanner using HREM (see fig. 2) on a transformed region in the stress field near a microcrack [20]. Recently neutron diffraction studies by Shapiro, Yang, Shirane, Noda \& Tanner indicated that there most probably exist two distinct versions of this long period superstructure [21,22]. The existence of these two versions was attributed by Yamada, Noda \& Fuchizaki to small local density fluctuations [23]. Also, the occurrence of the $(5, \overline{2})$ stacking was fitted in the concept of an adaptive phase following the stress-free condition of the austenite-martensite interface by Khatchaturyan, Shapiro \& Semenovskaya in 1991 [24]. One year later Murakami, Otsuka, Hanada \& Watanabe indeed showed perfect match between the theoretical predictions and experimental measurements on habit planes and orientation relationship for the stress induced $14 \mathrm{M}$ structure [25]. This year new stacking variants such as $14 \mathrm{M}, 12 \mathrm{M}$ and $10 \mathrm{M}$ were reported in ternary alloys of Ni-Al-Mn by Inoue, Morito, Murakami, Oda \& Otsuka [26].
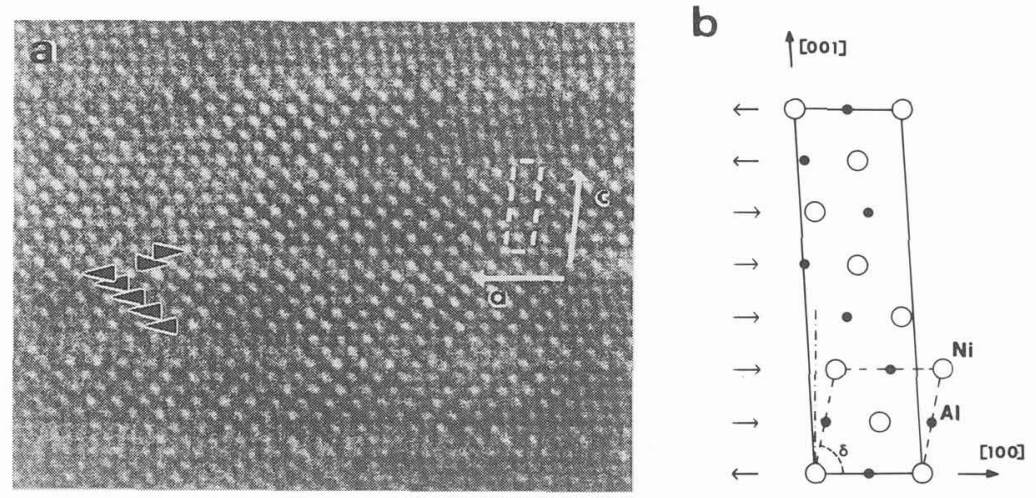

Figure 2. HREM image clearly showing the $(5, \overline{2})$ stacking (arrows point in shear direction) visible in the model.

In $\mathrm{Ni}$-Al the well characterised 14M stacking is observed at or below a Ni content of 62.5 at.\%. Under specific stress conditions, this stacking can also be found at higher Ni concentrations. The conditions for the other mentioned stackings, $2 \mathrm{O}$ and $10 \mathrm{M}$, are unclear at present. Above $63 \mathrm{at} \% \mathrm{Ni}$, the martensite plates are finely twinned on a single family of $\mathrm{L} 1_{0}$ close packed $\{111\}$ planes, i.e. the basal plane of the $2 \mathrm{M}$ structure. Actually the fine $(5, \overline{2})$ sequence is an ultimate example of extreme fine twinning. Each twin variant corresponds with one out of the three possible Bain distortions transforming the bcc austenite lattice into an fct martensite lattice. In most regular microtwin sequences the width $w$ of these twins is always extremely 
small, of the order of a few (14M structure) to about a few dozens of atom planes ( $2 \mathrm{M}$ structure). This immediately indicates that the surface energy of these microtwins is very small. In a recent study this surface energy was estimated by investigating the relation between the twin width and the twin length $L$, i.e. the plate size, for a given composition of 66 at\% $\mathrm{Ni}$ [27]. Indeed, from classic linearised as well as new non-linearised continuum models the twin surface energy can be calculated by relating the twin width with the interface energy at the martensite habit plane. In fig. 3 the $(w, L)$ measurements are fitted against the $1 / 2$ and $2 / 3$ power laws obtained from the linearised [28,29] and non-linearised [30] models, yielding a surface energy of $10^{-3}$ $\mathrm{J} / \mathrm{m}^{2}$ or $10^{-6} \mathrm{~J} / \mathrm{m}^{2}$, respectively, which is indeed very small and indicates that no interaction between adjacent twin planes exists.

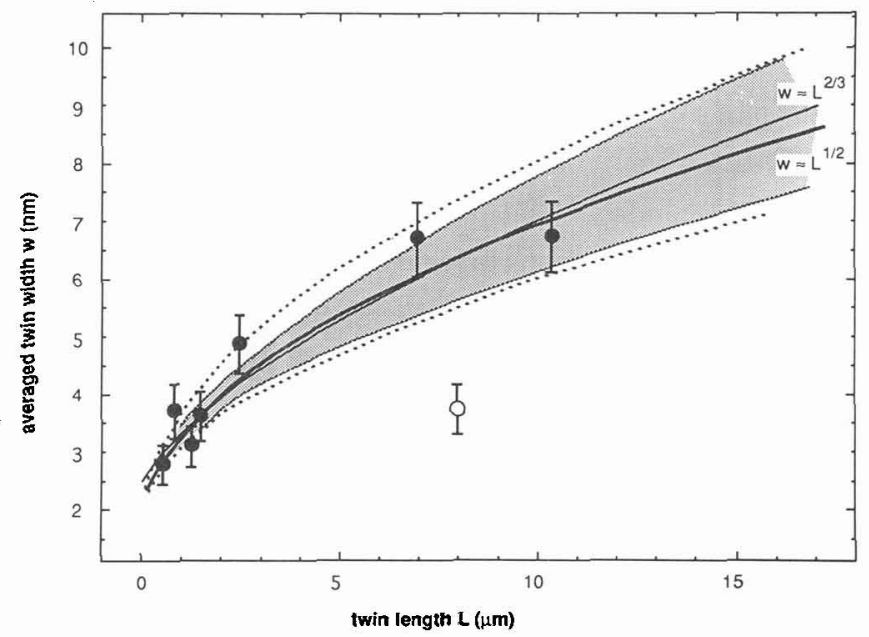

Figure 3. Fit of the microtwin width $w$ and length $L$ against the theoretically proposed $1 / 2$ and $2 / 3$ power laws.

Although both fits look equally valid, the non-linearised theory shows that in this regime of small surface energy the $2 / 3$ power law should apply. This implies, again according to this theory, that non-parallel microtwin planes should exist [30]. In other words, needle shaped twin variants or twin branching are expected to be observed when approaching an interface. An example hereof is shown in the HREM image of fig. 4 , where the width of one variant is seen to decrease, finally ending as a stacking fault inside the surrounding variant.

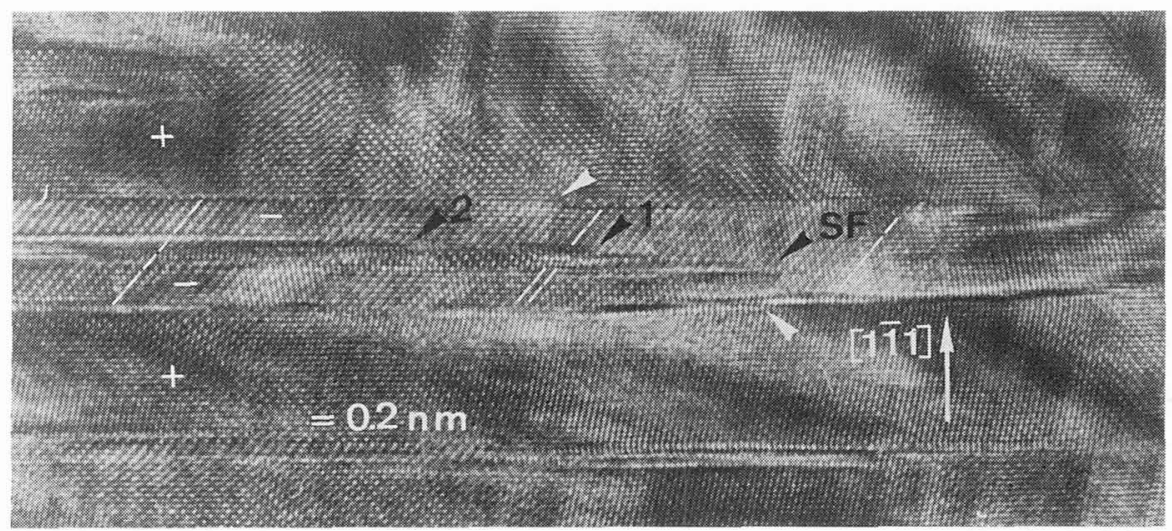

Figure 4. HREM image of a microtwin ending inside the martensite plate. 
In the same study the effect of the composition on the density of microtwins in plates with similar length scales was investigated. It was found that the average twin density slightly decreases with increasing $\mathrm{Ni}$ content, except for a steep decrease when going from the long period $(5, \overline{2})$ stacking to regularly twinned $2 \mathrm{M}$. This step is interpreted as a visualisation of the change in factors influencing the width of the twins. Indeed, in the same regime the c/a ratio of the fct lattice increases gradually, indicating a gradual increase in lattice distortion which is not believed to account completely for the abrupt change from $(5, \overline{2})$ to microtwinned $2 \mathrm{M}$. In the next chapter the existence of the $(5, \overline{2})$ stacking will be related to the observed precursor effects visible at the same composition.

\section{PRECURSORS IN Ni-Al}

Lasalmonie [31] was the first to present anomalies observed in the electron diffraction patterns of the $\mathrm{Ni}-\mathrm{Al}$ $\beta$ phase as well as a tweed-like contrast in the corresponding amplitude contrast images. Later Enami, Hasunuma, Nagasawa \& Nenno [32] interpreted these indications in real and reciprocal space as signs of premartensitic behaviour in view of their elastic softening measurements of the $C^{\prime}$ elastic constant of the $\beta$ phase. In 1983, Robertson \& Wayman presented at trilogy on tweed microstructures in the Ni-Al system studied by conventional transmission electron microscopy [33]. They concluded that tweed contrast is a manifestation of roughly sinusoidal $\{110\}<1 \overline{1} 0>$ static displacement waves having a range of wavelengths from about $1 \mathrm{~nm}$ to very large values and no definite phase relation with one another. The first lattice fringe image of the premartensitic phase in $\mathrm{Ni}-\mathrm{Al}$ was shown by Portier, Gratias \& Stobbs at the ICOMAT meeting in 1979 [34], where they noted a variability in the spacing of (110) fringes. To explain this observation they suggested a possible coupling of $\{110\}<1 \overline{1} 0>$ trallsverse acoustic phonons in the thin foil of the electron microscopy sample. Two meetings later, in 1986, Van Tendeloo, Chandrasekaran \& Lovey showed a much clearer two-dimensional lattice image of the premartensitic phase revealing contrast modulations that could be related to the diffuse streaks through optical diffractograms [35]. Schryvers \& Tanner showed that these contrast modulations are confined to small regions of a few $\mathrm{nm}$ [36]. The underlying atomic configuration was obtained on the basis of images as in fig. 5 and a superposition of a $\{110\}<1 \overline{10}>$ homogeneous shear and sinusoidal wave, with amplitudes decreasing towards the edges of the domain was suggested [36].

Here it is noted that the same shears as for the ensuing martensitic transformation are used and that the modulation wavelength is very close to the 7-layer periodicity of the 14M structure. In 1986 Shapiro, Larese, Noda, Moss \& Tanner [37] showed that the phonon dispersion curve for the [110]-TA 2 branch shows a small dip around the same $\xi$ value which further decreases when lowering the temperature towards $M_{S}$, but never reaches zero. In the limit $\zeta>0$ this mode corresponds with the elastic constant $C^{\prime}$ which is known to exhibit similar behaviour [32]. In conclusion these authors infer that the strain centres responsible for the elastic scattering are related to the phonon anomalies. As for these strain centres they envisage neartetragonal $14 \mathrm{M}$ embryos with an average size of $40 \AA$ at $329 \mathrm{~K}$ (cf. domains HREM image of fig. 5). The behaviour of elastic and inelastic neutron diffraction results as well as the possible precursing character of the strain centres is further documented by the same group $[21,21,38]$. Especially the effects of external stress on the phonon behaviour should be mentioned. As the stress is increased, the dip deepens and shifts to smaller wavelengths for 62.5 at.\% Ni [39], while for $60 \mathrm{at} \% \mathrm{Ni}$ a slight curb in the phonon branch develops into a strong dip at similar wavelengths [40]. The former result confirms EM results obtained by Schryvers 
\& Tanner near a crack tip [20]. All this strongly indicates that the electronic characteristics of the $\beta$ phase yield lattice distortions above $\mathrm{M}_{\mathrm{S}}$ that will, upon further cooling, develop into the final twinned martensite.
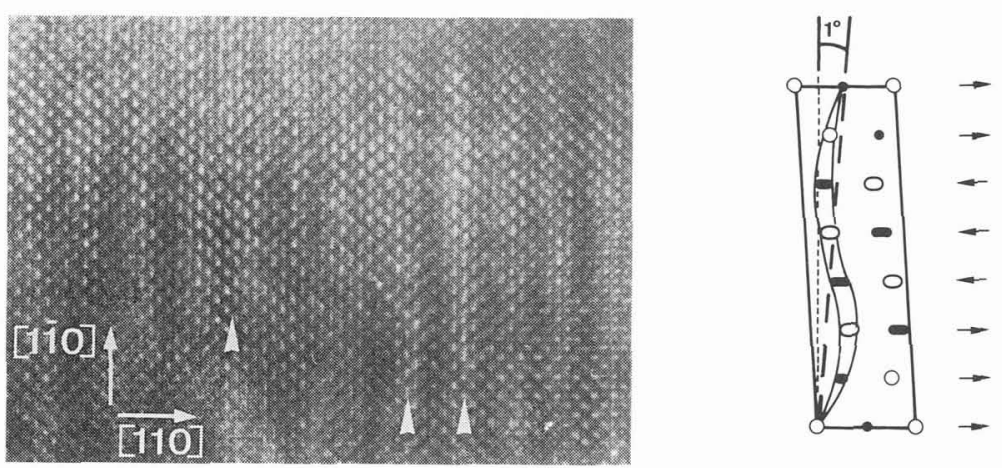

Figure 5. HREM image and proposed atomic model of a modulated B2 domain observed close to $\mathrm{M}_{\mathrm{S}}$.

Based on such experimental results Gooding \& Krumhansl recently presented an extensive theoretical treatment of the martensitic nucleation in Ni-Al [41]. They were indeed able to describe the $14 \mathrm{M}$ structure as a superposition of a homogeneous shear and a modulated distortion based on the coupling of the anisotropy and the phonon anomaly. In principle this coupling can exist without any pre-existing defects, however, the stress field produced by a local defect can in turn couple with the transformation strain. As shown by Becquart, Clapp \& Rifkin using molecular dynamics, heterogeneous defects such as the compositional disorder of excess $\mathrm{Ni}$ atoms on the Al sublattice could indeed induce the observed small distortions [42]. New support for these ideas has come from first-principles calculations by Zhao \& Harmon yielding the proper phonon anomalies which are attributed to the nesting of the Fermi-surface [43]. Also, recent results of NMR studies by Rubini, Dimitropoulos, Aldrovandi, Borsa, Torgeson \& Ziolo are interpreted in terms of a continuous formation of martensite with an incomplete degree of deformation [44], again confirming the above picture. An increasing degree of distortion when approaching the transition temperature was also observed in bulk thermal expansion experiments by Liu, Finlayson, Smith \& Tanner [45].

\section{THE METASTABLE $\mathrm{Ni}_{2} \mathrm{Al}$ PHASE}

Annealing the $\mathrm{Ni}-\mathrm{Al}$ austenite or martensite phases at moderate temperatures can yield different new phases. At 62.5 at. $\% \mathrm{Ni}$ a treatment around $400^{\circ} \mathrm{C}$, i.e. in the austenite regime, produces coherent, metastable precipitates that produce superreflections in reciprocal space, otherwise leaving the basic $\beta$ reflections unchanged. Until recently two models existed for this phase, both yielding the proper geometry for the diffraction patterns. The first, suggested by Lasalmonie, used a $\mathrm{q}=1 / 3<111>$ longitudinal wave yielding a classic $\omega$ structure [46], while in the second, proposed by Reynaud, the decrease in symmetry was completely explained by diffusion, resulting in a $\mathrm{Ni}_{2} \mathrm{Al}$ compound [47]. In a detailed HREM plus electron microdiffraction study Muto, Merk, Schryvers and Tanner showed that both phenomena are involved. The 
lattice image as shown in fig. $6 \mathrm{a}$ and obtained in extremely thin regions of the sample can only be explained by a partial $\omega$ collapse of an ordered $\mathrm{Ni}_{2} \mathrm{Al}$ structure [48]. In other words, both earlier suggestions were valid, they are now only being combined in the new model. It was also found by the same group that these $\mathrm{nm}$-sized precipitates do not hinder the martensitic transformations. Indeed, in transformed $2 \mathrm{M}$ material at 65 at.\% $\mathrm{Ni}$ and annealed above $\mathrm{M}_{\mathrm{S}}$ to form $\mathrm{Ni}_{2} \mathrm{Al}$ in the austenite, some precipitates are seen to be twinned as indicated in fig. $6 \mathrm{~b}$, following the microtwinning of the product phase [49]. The same conclusion was reached by Murthy \& Goo who also revealed the existence of $\mathrm{Ni} 2 \mathrm{Al}$ precipitates in $14 \mathrm{M}$ martensite [50,51].
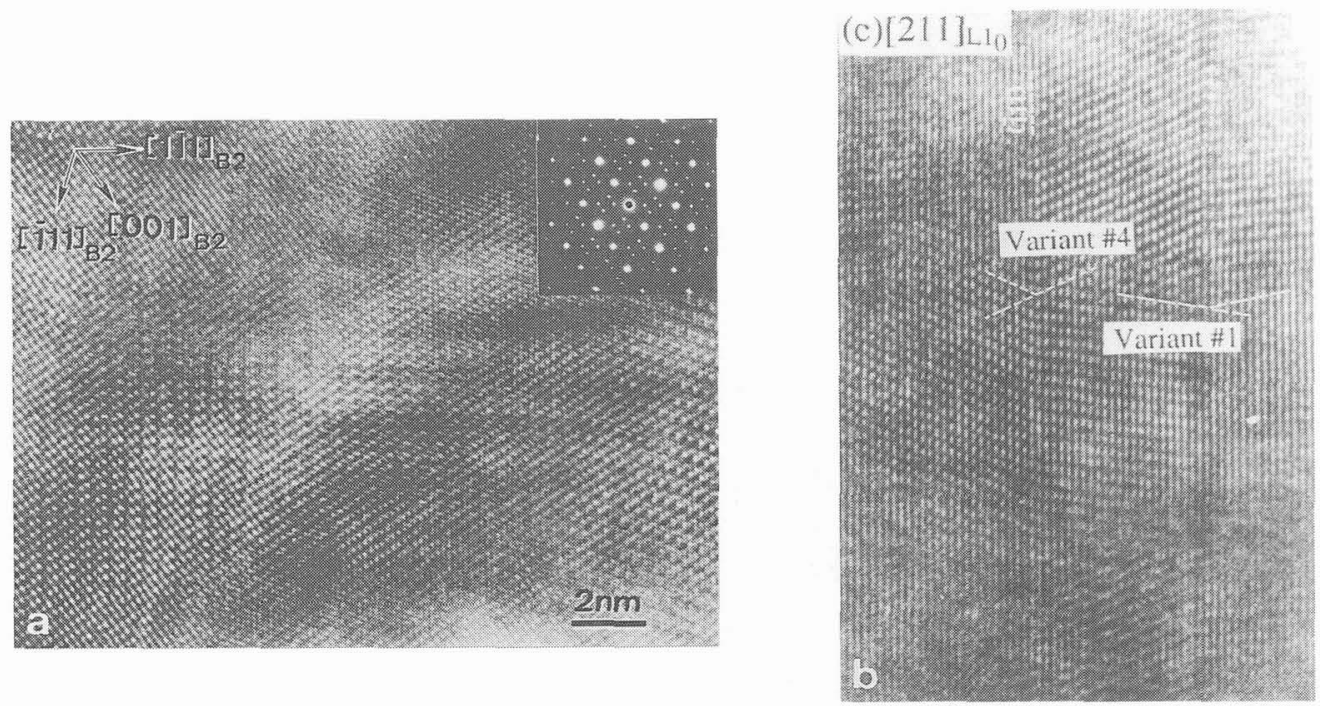

Figure 6. (a) HREM image of $\mathrm{Ni}_{2} \mathrm{Al}$ precipitates in the $\mathrm{B} 2$ matrix (62.5 at.\% $\mathrm{Ni}$ ) and (b) after the transformation of the $\mathrm{B} 2$ into $2 \mathrm{M}$ martensite ( 65 at.\% $\mathrm{Ni}$ ).

\section{THE BAINITIC $\mathrm{Ni}_{5} \mathrm{Al}_{3}$ PHASE}

Another phase which can be formed by annealing but which is found to affect the reversibility of the martensitic transformation is the orthorhombic $\mathrm{Ni}_{5} \mathrm{Al}_{3}$. This phase was first discovered by Enami \& Nenno in a Co contaminated Ni-Al sample [52] and later confirmed by Khadkikar \& Vedula in pure $\mathrm{Ni}_{65.3} \mathrm{Al}_{34.7}$ [53]. Its unit cell consists of four fet cells as shown in fig. 7a. The formation from the $\beta$ phase will thus consist of the same Bain distortion as for the $2 \mathrm{M}$ martensite coupled with a reordering process. Annealing for a few hours around $550{ }^{\circ} \mathrm{C}$ in the austenite phase of a 62.5 ar.\% sample produces small precipitates, often exhibiting specific symmetries by the combination of different variants of this phase. An example is given in the $<111>_{\beta}$ view of fig. $7 \mathrm{~b}$, where the three-fold symmetry is obtained by combining all three different Bain distortions two by two around a single twin plane, i.e. a former $\{110\}_{\beta}$ plane [54]. Still a large number of dislocations are found at the precipitate-matrix interface. Further annealing results in extended precipitates, showing different types of growth, depending on the combination of Bain distortions involved. Because of the slow speed of the transformation, larger plates surrounded by austenite can be retained in quenched samples. The HREM image of fig. 8 shows the interface between such a microtwinned plate and the austenite: no dislocations are observed at this habit plane. 

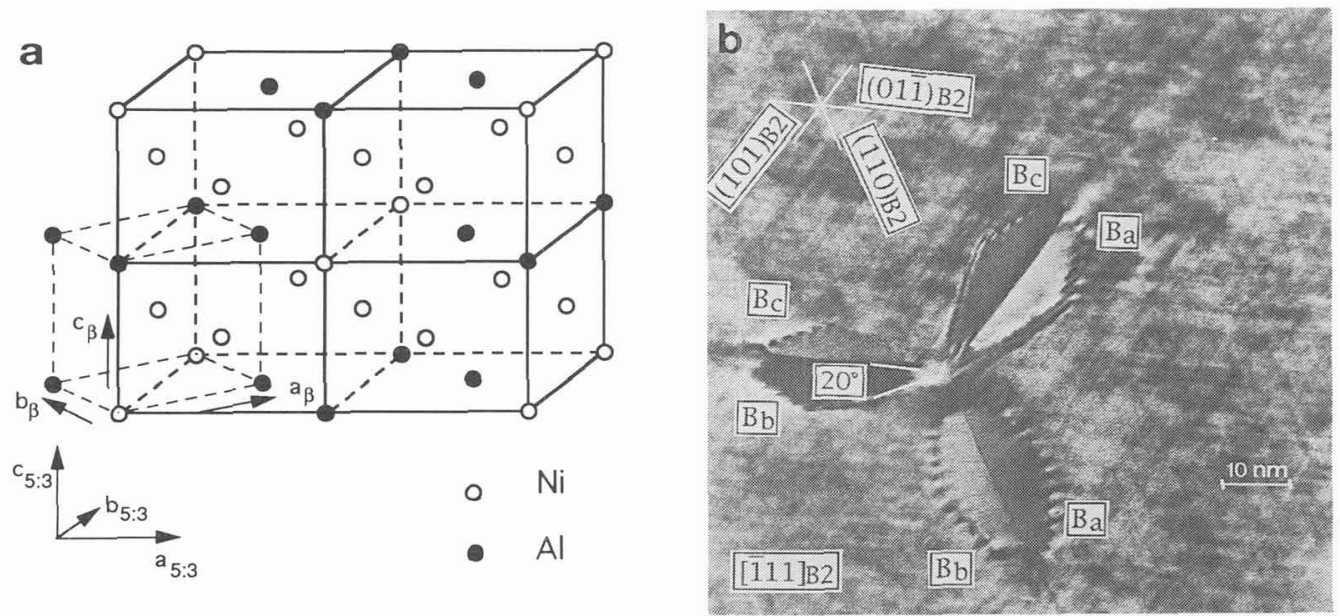

Figure 7. (a) Unit cell of the $\mathrm{Ni}_{5} \mathrm{Al}_{3}$ phase. (b) Three-fold precipitate of $\mathrm{Ni}_{5} \mathrm{Al}_{3}$ in a $\mathrm{B} 2$ matrix observed along $<111>\beta$.

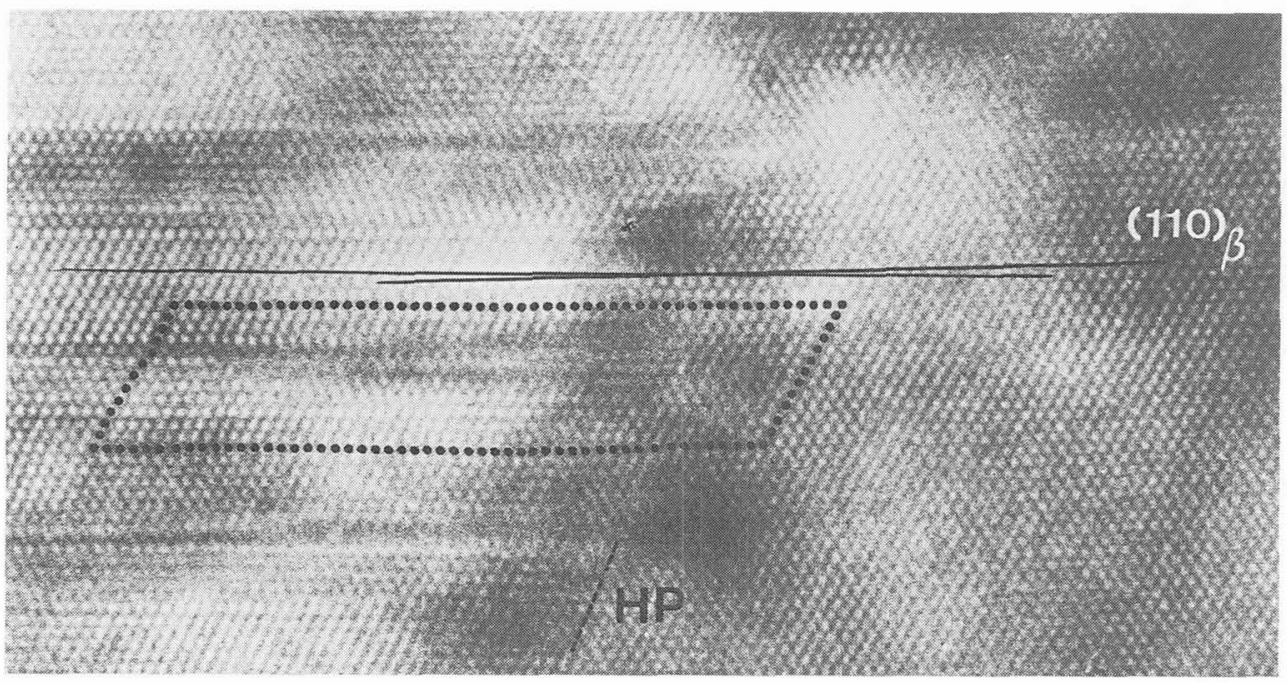

Figure 8. HREM image of a microtwinned $\mathrm{Ni}_{5} \mathrm{Al}_{3}$ plate inside austenite: no dislocations are found at the interface.

The crystallographic characteristics of the 5:3 plates are very similar to those of the $2 \mathrm{M}$ martensite plates, which is not surprising regarding the fact that they are both formed in the B2 austenite and have the same basic fet lattice. Another consequence of the latter correspondence is that annealing the martensite around $550^{\circ} \mathrm{C}$ for compositions where this is below $\mathrm{A}_{\mathrm{S}}$ reorders the $\mathrm{L} 1_{0}$ ordering into the $\mathrm{Ni}_{5} \mathrm{Al}_{3}$ one [54]. Some of the effects of this reordering on the overall transformation characteristics and shape memory behaviour of Ni-Al have already been investigated by Maas, Toth, Hamers and Beyer [55], Khadkikar, Locci, Vedula \& Michal [56] and Robertson, Yang \& Wayman [57,58].

\section{Acknowledgement}

I like to thank Lee Tanner for many ongoing years of valuable suggestions and stimulating discussions. 


\section{References}

[1] Becker K. and Ebert F., Z. Physik 16 (1923) 165-169.

[2] Gwyer A.G.C., Z. Anorg. Chem. 57 (1908) 133-153.

[3] Bradley A.J. and Taylor A., Proc. Roy. Soc. Lon. A 159 (1937) 56-72.

[4] Guseva L.N. and Makarov E.S., Dokl. Akad. Nauk SSSR 77 (1951) 615-616 (abstr. transl. in Chem. Abstr. 47 (1951) 6211-6212).

[5] Maxwell W.A. and Grala E.M., NACA TN 3259 (1954).

[6] Rosen S. and Goebel J.A., Trans. Met. Soc. AIME 242 (1968) 722-724.

[7] Enami K., Nenno S. and Shimizu K., Trans. JIM 14 (1973) 161-165.

[8] Mohanty G.P. and Rath B.B., 30 h annual EMSA meeting, Texas (1972) pp. 584-586.

[9] Chakravorty S. and Wayman C.M., Metall. Trans. A 7 (1976) 555-568, 569-582.

[10] Bowles J.S. and Mackenzie J.K., Acta Metall. 2 (1954) 129-137, 224-234.

[11] Mackenzie J.K. and Bowles J.S., Acta Metall. 2 (1954) 138-147.

[12] Enami K. and Nenno S., Metall. Trans. 2 (1971) 1487-1490.

[13] Au Y.K. and Wayman C.M., Scripta Metall. 6 (1972) 1209-1214.

[14] Otsuka K., Ohba T., Tokonami M. and Wayman C.M., Scripta metall. mater. 29 (1993) 1359-1364.

[15] Chandrasekaran M. and Mukherjee K., Mat. Sci. Eng. 13 (1974) 197-201.

[16] Chandrasekaran M. and Delaey L., ICOMAT, Leuven 1982 (J. Phys. C4) pp. 661-665.

[17] Reynaud F., Scripta Metall. 11 (1977) 765-770.

[18] Martynov V.V., Enami K., Khandros L.G., Nenno S. and Tkachenko A.V., Phys. Met. Metall. 55 (1983) 136-143.

[19] Martynov V.V., Enami K., Khandros L.G., Tkachenko A.V. and Nenno S., Scripta Metall. 17 (1983) 1167-1173.

[20] Schryvers D. and Tanner L.E., MRS vol. 246, Shape Memory Materials and Phenomena, Boston 1991, pp. 33-38.

[21] Shapiro S.M., Yang B.X., Shirane G., Noda Y. and Tanner L.E., Phys. Rev. Lett. 62 (1989) 1298-1301.

[22] Noda Y., Shapiro S.M., Shirane G., Y. Yamada and Tanner L.E., Phys. Rev. B 42 (1990) 10397-10404.

[23] Yamada Y., Noda Y. and Fuchizaki K., Phys. Rev. B 42 (1990) 10405-10414.

[24] Khatchaturyan A., Shapiro S.M. and Semenovskaya S., Phys. Rev. B 43 (1991) 10832-10843.

[25] Murakami Y., Otsuka K., Hanada S. and Watanabe S., Mat. Trans. JIM 33 (1992) 282-288.

[26] Inoue T., Morito S., Murakami Y., Oda K. and Otsuka K., Materials Lett. 19 (1994) 33-37.

[27] Schryvers D., Phil. Mag. A. 68 (1993) 1017-1032.

[28] Khatchaturyan A.G. and Shatalov G.A., Soviet Phys. JETP 29 (1969) 557-571.

[29] Roitburd A.L., Soviet Phys. Solid St. 10 (1969) 2870-2887.

[30] Kohn B. and Müller S. , Phil. Mag. A 66 (1992) 697-715.

[31] Lasalmonie A., C. R. Acad. Sc. Paris 280 (1975) C 1501-1504.

[32] Enami K., Hasunuma J., Nagasawa A. and Nenno S., Scripta Metall. 10 (1976) 879-884.

[33] Robertson I.M. and Wayman C.M., Phil. Mag. 48 (1983) 421-442, 443-467, 629-647. 
[34] Portier R., Gratias D. and Stobbs W.M., ICOMAT 1979 (Cambridge, USA) pp. 541-545.

[35] Van Tendeloo G., Chandrasekaran M. and Lovey F.C., ICOMAT, Nara 1986, pp. 868-870.

[36] Schryvers D. and Tanner L.E., Ultramicroscopy 32 (1990) 241-254.

[37] Shapiro S.M., Larese J.Z., Noda Y., Moss S.C. and Tanner L.E., Phys. Rev. Lett. 57 (1986) 3199-3202.

[38] Shapiro S.M., Yang B.X., Shirane G., Larese J.Z., Tanner L.E. and Moss S.C., Physica B 156 \& 157 (1989) 59-61.

[39] Shapiro S.M., Svensson E.C., Vettier C. and Hennion B., Phys. Rev. B 48 (1993) 13223-13229.

[40] Ye L., Shapiro S.M. and Chou H, Scripta metall. mater. (accepted).

[41] Gooding R.J. and Krumhansl J.A., Phys. Rev. B 39 (1989) 1535-1540.

[42] Becquart C.S., Clapp P.C. and Rifkin J.A., Phys. Rev. B 48 (1993) 6-13.

[43] Zhao G.L. and Harmon B., Phys. Rev. B 45 (1992) $2818-2824$.

[44] Rubini S., Dimitropoulos C., Aldrovandi S., Borsa F., Torgeson D.R. and Ziolo J., Phys. Rev. B 46 (1992) 10563-10572.

[45] Liu M., Finlayson T.R., Smith T.F. and Tanner L.E., Mat. Sci. Eng. A 157 (1992) 225-232.

[46] Lasalmonie A., Scripta Metall. 11 (1977) 527-529.

[47] Reynaud F., J. Appl. Cryst. 9 (1976) $263-266$.

[48] Muto S., Merk N., Schryvers D. and Tanner L.E., Phil. Mag. B 67 (1993) 673-689.

[49] Muto S., Schryvers D., Merk N. and Tanner L.E., Acta metall. mater. 41 (1993) 2377-2383.

[50] Murthy A.S. and Goo E., Metall. Mater. Trans, A 25 (1994) 57-61.

[51] Murthy A.S. and Goo E., Acta metall. mater. 41 (1993) 2135-2142.

[52] Enami K. and Nenno S., Trans. IIM 19 (1978) 571-580.

[53] Khadkikar P.S. and Vedula K., J. Mater. Res. 2 (1987) 163-167.

[54] Schryvers D., Toth L. Ma Y. and Taniner L.E., these proceedings.

[55] Maas J.H., Toth L., Hamers A.A.H. and Beyer J., ESOMAT Aussois 1991 (J. Phys IV C4, 1991) pp. 373-378.

[56] Khadkikar P.S., Locci I.E., Vedula K. and Michal G.M., Metall. Trans. A 24 (1993) 83-94.

[57] Robertson I.M. and Wayman C.M., Metallography 17 (1984) 43-55.

[58] Yang J.H. and Wayman C.M., Mat. Sci. and Eng. A 160 (1993) 241-249. 